\title{
PRODUÇÃO DA BATATA-DOCE ADUBADA COM ESTERCO BOVINO E BIOFERTILIZANTE ${ }^{1}$
}

\author{
Yield of sweet potato (Ipomoea batatas (L.) Lam.) fertilized with cattle manure and biofertilizer
}

\author{
Ademar Pereira de Oliveira ${ }^{2}$, Arthur Hennys Diniz Barbosa ${ }^{3}$, Lourival Ferreira Cavalcante ${ }^{4}$, \\ Walter Esfraim Pereira ${ }^{5}$, Arnaldo Nonato Pereira de Oliveira $^{6}$
}

\begin{abstract}
RESUMO
Objetivou-se avaliar a produção da batata-doce (Ipomoea batatas (L.) Lam.) adubada com esterco bovino e biofertilizante, conduziu-se um experimento no período de Janeiro a Junho de 2004, em NEOSSOLO REGOLÍTICO, psamítico típico, na Universidade Federal da Paraíba, em Areia-PB. O delineamento experimental empregado foi de blocos casualisados, com quatro repetições com os tratamentos distribuídos em arranjo fatorial $6 \times 2$, sendo seis doses de esterco bovino $\left(0,10,20,30,40,50 \mathrm{t}^{-1}\right)$ e ausência e presença de biofertilizante. As parcelas foram constituídas por 80 plantas, espaçadas de 80 x $30 \mathrm{~cm}$. O número de raízes comerciais por planta atingiu valores máximos estimados de 2,0 e 1,7 raízes, respectivamente, nas doses de 26 e $25 \mathrm{t} \mathrm{ha}^{-1}$ de esterco bovino na presença e ausência de biofertilizante. O peso médio de raízes comerciais da batata-doce aumentou com elevação das doses de esterco bovino, atingindo na maior dose 360 e $224 \mathrm{~g}$ na presença e ausência de biofertilizante. As doses de 25,6 e 24,4 t ha ${ }^{-1}$ de esterco bovino foram responsáveis pela máxima produção total de raízes de 21,4 e 21,2 t ha ${ }^{-1}$, respectivamente, na presença e ausência de biofertilizante. As máximas produções de raízes comerciais, 15,2 e 12,9 $\mathrm{t} \mathrm{ha}^{-1}$ foram alcançadas com 25,5 e 21,3 $\mathrm{t} \mathrm{ha}^{-1}$ de esterco bovino, na presença e ausência de biofertilizante, respectivamente.
\end{abstract}

Termos para indexação: Ipomoea batatas, adubação orgânica, rendimento.

\section{ABSTRACT}

Aiming to evaluate the sweet potato (Ipomoea batatas (L.) Lam.) yield fertilization with bovine manure and biofertilizer, an experiment was carried out from January to July, 2004, on USTIPSAMMENT soil, at Universidade Federal da Paraíba, Areia-PB. The Experimental outline used was randomized blocks, with four replications and, treatments distributed in factorial arrangement 6 $\mathrm{x} 2$, being six levels of bovine manure $\left(0,10,20,30,40,50 \mathrm{tha}^{-1}\right)$ and absence and presence of biofertilizer. Plots were constituted by 80 plants, spaced $80 \times 30 \mathrm{~cm}$. Commercial roots number per plant reached maximum values estimated of 2.0 and 1.7 roots, respectively, on levels of $26 \mathrm{e} 25 \mathrm{t} \mathrm{ha}^{-1}$ of bovine manure in presence and absence of biofertilizer. The medium weight of commercial roots of sweet potato increased, with elevation of bovine manure levels, with maximum weights of $360 \mathrm{e} 224 \mathrm{~g}$, in presence and absence of biofertilizer. The levels of 25.6 and $24.4 \mathrm{t} \mathrm{ha}^{-1}$ of bovine manure, in presence and absence of biofertilizer, presented the maximum of total yield of 21.4 and $21.2 \mathrm{t} \mathrm{ha}^{-1}$, respectively. Maximum yield of commercial roots, 15.2 and $12.9 \mathrm{t} \mathrm{ha}^{-1}$ were reached with 25.5 and $21.3 \mathrm{t} \mathrm{ha}^{-1}$ of bovine manure, under presence and absence of biofertilizer, respectively.

Index terms: Ipomoea batatas, organic fertilization, revenue.

(Recebido em 31 de julho de 2006 e aprovado em 1 de junho de 2007)

\section{INTRODUÇÃO}

No Brasil, a batata-doce (Ipomoea batatas (L.) Lam.) é cultivada em praticamente todos os estados, principalmente nas Regiões Sul e Nordeste, onde se constitui em uma das mais importantes fontes de alimento. No estado da Paraíba, é mais cultivada e difundida nas regiões próximas aos grandes centros consumidores, sendo o estado, considerado o maior produtor nordestino e o quarto em nível nacional (SOARES et al., 2002). Apesar desse destaque, é paradoxalmente a nível nacional, um dos estados que possui uma das mais baixas produtividades, em torno de 6,8 t ha ${ }^{-1}$. A falta de um programa de adubação para a cultura, é um dos principais fatores responsáveis pela baixa produtividade (SILVA et al., 2002).

\footnotetext{
${ }^{1}$ Parte da dissertação apresentada ao Programa de Pós-Graduação em Agronomia do CCA-UFPB pelo segundo autor.

${ }^{2}$ Professor, Doutor - Departamento de Fitotecnia/DF - Universidade Federal da Paraíba/UFPB - Cx. P. 02 - 58397-000 - Areia, PB - ademar@cca.ufpb.br Bolsista de Produtividade em Pesquisa CNPq

${ }^{3}$ Mestrando em Agronomia - Departamento de Fitotecnia/DF - Universidade Federal da Paraíba/UFPB - Cx. P. 02 - 58397-000 - Areia, PB hennys@cca.ufpb.br

${ }^{4}$ Doutor - Departamento de Solos e Engenharia Rural/DSER - Universidade Federal da Paraíba/UFPB - 58397-000 - Areia, PB - lofeca@cca.ufpb.br Bolsista de Produtividade em Pesquisa CNPq

${ }_{5}^{5}$ Professor, Doutor - Departamento de Ciências Fundamentais e Sociais/DCFS - Universidade Federal da Paraíba/UFPB - 58397-000 - Areia, PB wep@cca.ufpb.br

${ }^{6}$ Graduando em Agronomia - Departamento de Fitotecnia/DF - Universidade Federal da Paraíba/UFPB - 58397-000 - Areia, PB arnaldo_nonato@hotmail.com - Bolsista de Iniciação Científica CNPq
} 
A utilização de adubos orgânicos de origem animal é considerada uma prática útil e econômica para os produtores de hortaliças, pois favorece a fertilidade e a conservação do solo e proporcionam acúmulo de nitrogênio orgânico no solo, aumentando seu potencial de mineralização e sua disponibilidade para as plantas (GALVÃO et al., 1999). No entanto, maiores ou menores doses a serem utilizadas dependerão do tipo, textura, estrutura e teor da matéria orgânica do solo (TRANI et al., 1997).

As hortaliças são beneficiadas pelo emprego de adubos orgânicos, tanto em produtividade como em qualidade dos produtos obtidos, sendo o esterco bovino a fonte mais utilizada, especialmente em solos pobres em matéria orgânica (FILGUEIRA, 2000). Isso porque elas atuam como poderoso agente beneficiador do solo, capaz de melhorar substancialmente muitas de suas características físicas e químicas (FERREIRA et al., 1993).

Em algumas hortaliças, cujas partes comerciais são as raízes, tem-se verificado efeitos positivos do emprego da adubação orgânica na produtividade. Na cenoura, Praxedes (2000) verificou maiores incrementos na produção nos tratamentos que receberam esterco bovino e esterco mais biofertilizante produzindo, respectivamente, 22,0 e 20,3 t ha ${ }^{-1}$ de raízes. Na batata-doce, Hollanda (1990) observou produção de raízes com máxima eficiência econômica, com aplicação de $40 \mathrm{t} \mathrm{ha}^{-1}$ de esterco bovino, e Freitas et al. (1999) obtiveram resposta positiva à aplicação de doses de composto orgânico sobre o incremento na produção de raízes.

Outra prática que tem se mostrado útil e de baixo custo é o emprego de biofertilizantes, preparados a partir da digestão aeróbica ou anaeróbica de materiais orgânicos. Esses adubos líquidos têm sido usados na agricultura orgânica em substituição aos fertilizantes minerais (FERNANDES et al., 2000), como forma de manter o equilíbrio nutricional de plantas e torná-las menos suscetíveis ao ataque de pragas e de patógenos (SANTOS, 2001).

Em plantas de ciclo curto como as olerícolas, o uso de biofertilizantes deve ser feito em pulverizações semanais, para permitir um bom desenvolvimento das mesmas, que exigem complementação mais rápida e eficiente dos nutrientes (SANTOS, 1992). Em pepino, berinjela, tomate, alface e pimentão, Pinheiro \& Barreto (2000) obtiveram aumentos na produção comercial em função de pulverizações com biofertilizante, produzido com esterco bovino na concentração de $20 \%$, tanto em estufas como em condições de campo aberto. $\mathrm{Na}$ batata-doce, as informações sobre o uso de biofertilizantes praticamente não existem, o que justifica a necessidade de se realizar pesquisas, para viabilizar seu emprego como fertilização alternativa.

Objetivou-se avaliar a produção da batata-doce em diferentes doses de esterco bovino aplicada ao solo, na presença e ausência de biofertilizante fornecido e via foliar.

\section{MATERIAL E MÉTODOS}

O trabalho foi realizado no período de janeiro a junho de 2004, na Universidade Federal da Paraíba, em Areia-PB, localizado na microrregião do Brejo Paraibano. Pela classificação de Koppen, o clima é do tipo AS'(quente e úmido), precipitação pluviométrica média anual em torno de $1.400 \mathrm{~mm}$ e temperatura média anual entre $23^{\circ}$ e $24^{\circ} \mathrm{C}$.

O solo foi classificado como NEOSSOLO REGOLÍTICO, psamítico típico, textura franca - arenosa (EMBRAPA, 1999), com as seguintes características química e física: $\mathrm{pH}$ em $\mathrm{H}_{2} \mathrm{O}=5,9 ; \mathrm{P}$ disponível = 43,13 mg dm${ }^{-3} ; \mathrm{K}=$ $73,05 \mathrm{mg} \mathrm{dm}^{-3} ;$ Al trocável $=0,0 \mathrm{cmol} \mathrm{dm}^{-3} ; \mathrm{Ca}+\mathrm{Mg}=3,45$ $\mathrm{cmol}_{\mathrm{c}} \mathrm{dm}^{-3}$; matéria orgânica $=15,8 \mathrm{~g} \mathrm{~kg}^{-1}$; carbono orgânico $=9,16 \mathrm{~g} \mathrm{~kg}^{-1}$; areia $=841,50 \mathrm{~g} \mathrm{~kg}^{-1} ;$ silte $=88,00 \mathrm{~g} \mathrm{~kg}^{-1} ;$ argila $=70,50 \mathrm{~g} \mathrm{~kg}^{-1}$; densidade global $=1,37 \mathrm{~g} \mathrm{~cm}^{-3}$; densidade de partículas $=2,61 \mathrm{~g} \mathrm{dm}^{-3}$; e porosidade total $=0,47 \mathrm{~m}^{3} \mathrm{~m}^{-3} . \mathrm{O}$ esterco bovino apresentava as seguintes características: $\mathrm{P}_{2} \mathrm{O}_{5}=3,60 \mathrm{~g} \mathrm{~kg}^{-1} ; \mathrm{K}_{2} \mathrm{O}=4,10 \mathrm{~g} \mathrm{~kg}^{-1} ; \mathrm{N}=7,20 \mathrm{~g} \mathrm{~kg}^{-1}$; matéria orgânica $=182,07 \mathrm{~g} \mathrm{~kg}^{-1}$ e relação $\mathrm{C} / \mathrm{N}=14 / 1$ e o biofertilizante a seguinte composição de macronutrientes em $\mathrm{g} \mathrm{L}^{-1}: \mathrm{N}=$ 0,76; $\mathrm{P}=0,22 ; \mathrm{K}=0,27 ; \mathrm{Ca}=0,21 ; \mathrm{Mg}=0,13$ e $\mathrm{S}=0,32$. O solo foi preparado por meio de aração, gradagem e confecção de leirões, com auxílio de enxadas.

O delineamento experimental empregado foi o de blocos casualizados, com quatro repetições em esquema fatorial $6 \times 2$, sendo seis doses de esterco bovino $(0,10,20$, $30,40,50 \mathrm{t} \mathrm{ha}^{-1}$ ) e ausência e presença de biofertilizante. A unidade experimental foi constituída por 80 plantas distribuídas em quatro leirões de 20 plantas cada, espaçadas de 80 × $30 \mathrm{~cm}$, sendo consideradas para efeito de avaliações, as 40 plantas centrais.

A adubação de plantio constou apenas da aplicação das doses de esterco bovino (devidamente curtido), descritas no delineamento experimental, incorporadas nos leirões, quinze dias antes do plantio. O biofertilizante foi aplicado no solo aos 15, 30, 45, 60 e 75 dias após o plantio, na concentração de $10 \%$ (dois litros de biofertilizante, em 20 litros de água), ao lado das plantas. Foram necessários cinco litros da concentração para distribuição uniforme nas plantas.

O biofertilizante foi preparado por meio da fermentação contendo esterco bovino fresco e água na proporção de $50 \%($ volume/volume = v/v), por um período 
de trinta dias, em recipiente plástico, na ausência de ar. Para se obter o sistema anaeróbio, a mistura foi colocada em uma bombona plástica de 200 litros deixando-se um espaço vazio de 15 a $20 \mathrm{~cm}$ no seu interior e fechada hermeticamente. Na tampa foi adaptada uma mangueira com a outra extremidade mergulhada num recipiente com água na altura de $20 \mathrm{~cm}$, para a saída de gases (SANTOS, 1992).

No plantio foram utilizadas ramas de batata-doce, variedade Rainha Branca, com aproximadamente $40 \mathrm{~cm}$ de comprimento. Essas ramas, retiradas de viveiro, em área próxima ao experimento, foram cortadas com um dia de antecedência para facilitar o manejo e enterradas pela base, com auxílio de um pequeno gancho, na profundidade de 10 a $12 \mathrm{~cm}$.

Durante a condução do experimento foram realizadas irrigações pelo sistema de aspersão convencional, nos períodos de ausência de precipitação, procurando fornecer à cultura umidade suficiente para seu pleno desenvolvimento, com turno de rega de duas vezes por semana. As capinas foram manuais com o auxílio de enxadas, mantendo a cultura sempre livre da concorrência de plantas daninhas. Não foi realizado controle fitossanitário em decorrência da ausência de pragas e doenças.

A colheita foi realizada aos 120 dias após o plantio, quando avaliou-se o número de raízes comerciais por planta, peso médio de raízes comercias, produção total e comercial de raízes. A produção comercial correspondeu ao peso das raízes de formato uniforme, lisas com peso igual ou superior a $80 \mathrm{~g}$, conforme Embrapa (1995). Os resultados foram submetidos à análises de variância e de regressão, com a significância testada através do teste $\mathrm{F}$, com até $5 \%$ de probabilidade.

\section{RESULTADOS E DISCUSSÃO}

Ocorreram respostas significativas $(\mathrm{P}<0,05)$ pelo teste $\mathrm{F}$ da interação entre esterco bovino e biofertilizante, para todas as caracteríscas avaliadas. No desdobramento das interações, as médias do número de raízes comerciais por planta e das produções total e comercial de raízes, ajustaram-se a modelos quadráticos de regressão; enquanto as médias para o peso médio de raízes aumentaram de forma linear em função das doses de esterco bovino, na presença e ausência de biofertilizante.

O número de raízes comerciais por planta atingiu valores máximos estimados de 2,0 e 1,7 raízes, respectivamente, nas doses de 26 e $25 \mathrm{t} \mathrm{ha}^{-1}$ de esterco bovino na presença e ausência de biofertilizante (Figura 1). Esses resultados evidenciam que embora o esterco bovino seja um forte aliado na melhoria da produção de batata-doce (CHAVES \& PEREIRA, 1985), sua combinação com biofertilizante, deve ser recomendada na fertilização orgânica, para aumentar o número de raízes comerciais por planta. Como a diferença entre o número de raízes formadas na presença e ausência de biofertilizante foi pequena, o emprego apenas do esterco bovino atende a esse propósito.

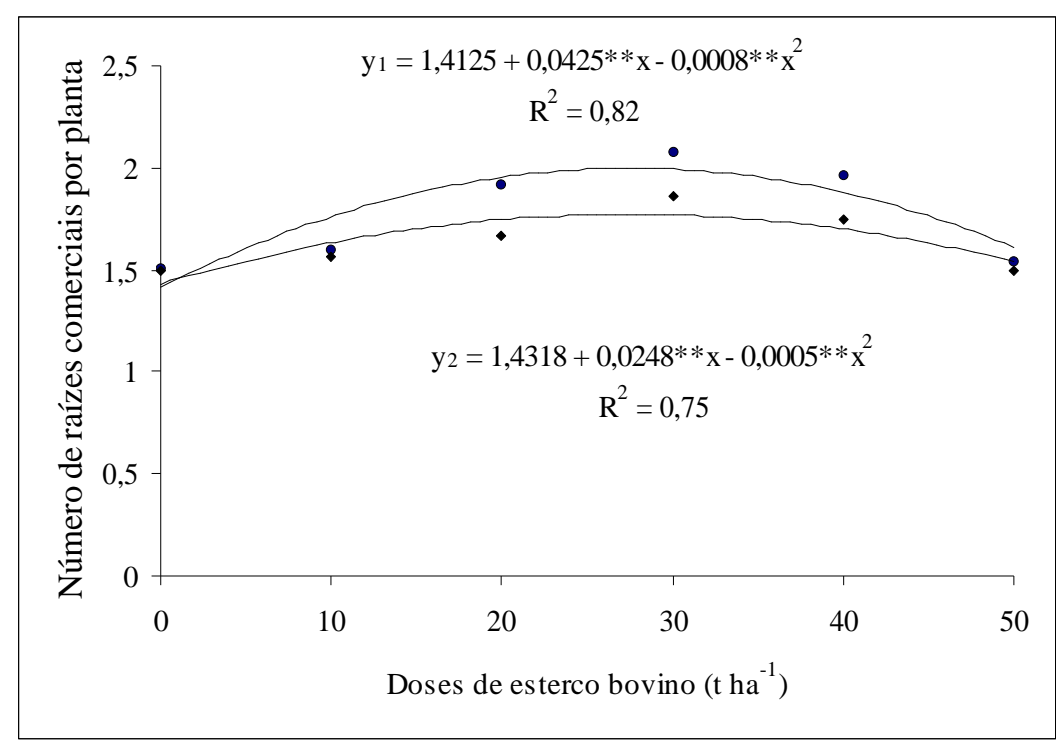

Figura 1 - Número de raízes comerciais por planta de batata-doce em função de doses de esterco bovino-presença $\left(\mathrm{y}_{1}\right)$ e ausência $\left(\mathrm{y}_{2}\right)$ de biofertilizante. CCA-UFPB, Areia, 2005. 
O peso médio de raízes comerciais da batata-doce aumentou na proporção de 1,85 e $0,95 \mathrm{~g}$ com elevação das doses de esterco bovino, com valores de 360 e $224 \mathrm{~g}$, na maior dose estudada, na presença e ausência de biofertilizante, respectivamente (Figura 2). As doses fornecidas não permitiram alcançar o peso máximo de raízes comerciais. Porém, nas condições em que realizou-se o presente trabalho, observou-se maior eficiência do esterco bovino em elevar o peso médio de raízes comerciais em batata-doce, quando associado ao biofertilizante. Souza (1990) trabalhando com adubação orgânica em cenoura obteve respostas positivas do emprego apenas do esterco bovino, sobre a elevação do peso médio de raízes comerciais, e Seno et al. (1996) avaliando esterco de galinha e fósforo no alho, veficaram efeito apenas do esterco, na elevação do peso médio de bulbos.

As doses estimadas de 25,6 e 24,4 $\mathrm{t} \mathrm{ha}^{-1}$ de esterco bovino, na presença e ausência de biofertilizante foram responsáveis pelas máximas produções total de raízes de 21,4 e $21,2 \mathrm{t} \mathrm{ha}^{-1}$, respectivamente (Figura 3). As produções máximas estimadas de raízes comerciais 15,2 e 12,9 t ha ${ }^{-1}$ foram alcançadas com 25,5 e 21,3 $\mathrm{t} \mathrm{ha}^{-1}$ de esterco bovino, na presença e ausência de biofertilizante, respectivamente (Figura 4).

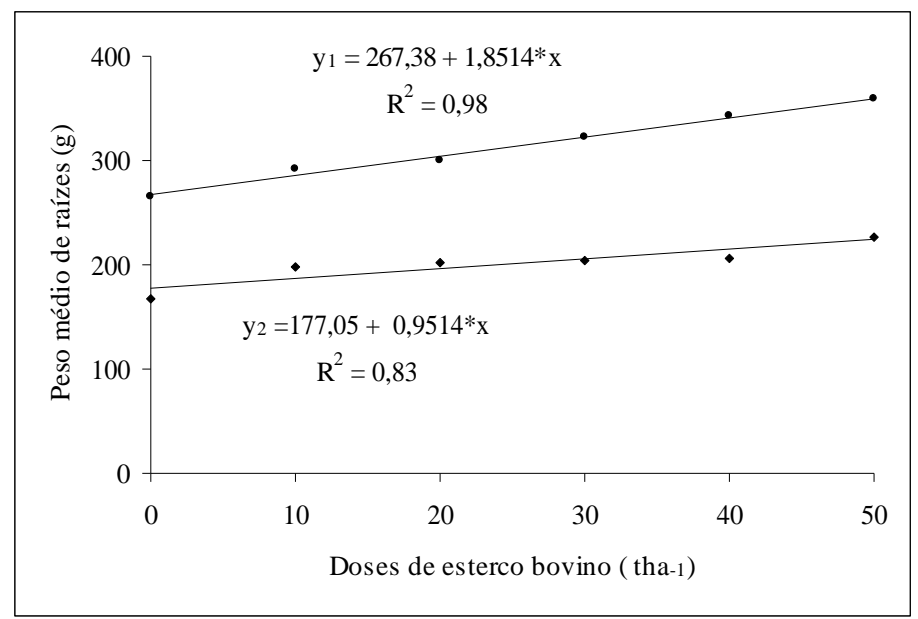

Figura 2 - Peso médio de raízes comerciais de batata-doce, em função de doses de esterco bovino, na presença $\left(\mathrm{y}_{1}\right)$ e ausência $\left(\mathrm{y}_{2}\right)$ de biofertilizante. CCA-UFPB, Areia, 2005.

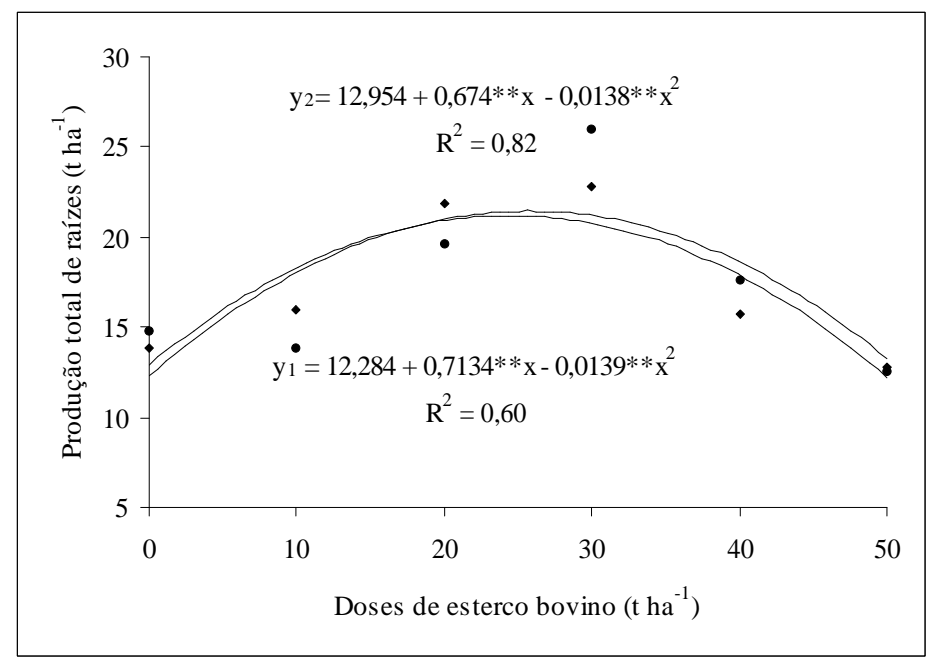

Figura 3 - Produção total de raízes de batata-doce em função de doses de esterco bovino, na ausência $\left(\mathrm{y}_{1}\right)$ e presença $\left(\mathrm{y}_{2}\right)$ de biofertilizante. CCA-UFPB, Areia, 2005. 


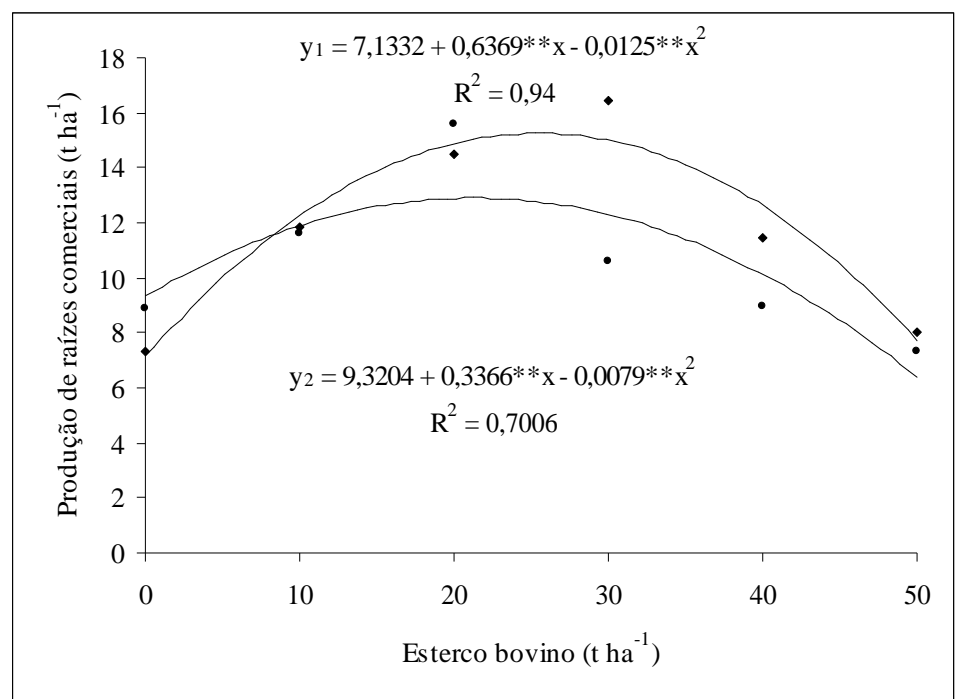

Figura 4 - Produção de raízes comerciais de batata-doce em função de doses de esterco bovino, na presença $\left(\mathrm{y}_{1}\right)$ e ausência de biofertilizante $\left(\mathrm{y}_{2}\right)$. CCA-UFPB, Areia, 2005.

As produções de raízes foram superiores nos tratamentos onde o esterco bovino foi associado ao biofertilizante, em relação àquelas alcançadas apenas com o uso do esterco bovino. Porém, todas as produções de raízes comerciais superaram a produtividade média da batata-doce, para o estado da Paraíba que é de $6,8 \mathrm{t} \mathrm{ha}^{-1}$ (SILVA et al., 2002) e a média nacional de $10 \mathrm{t} \mathrm{ha}^{-1}$ (SOARES et al., 2002), demonstrando que o uso do esterco bovino quer de forma isolada ou associado com biofertilizante foi eficiente em aumentar a produção da batata-doce.

A eficiência do esterco bovino em elevar a produção de raízes comerciais de batata-doce, possivelmente esteja relacionada à sua composição química e melhoria das qualidades físicas e biológicas do solo, pelo fornecimento de nutrientes, como nitrogênio, fósforo e potássio, melhorando as condições químicas para o desenvolvimento das raízes (FILGUEIRA, 2000). Santos et al. (2006) obtiveram aumento de $23 \%$ na produção de raízes comerciais de batata-doce apenas com o emprego de esterco bovino na dose de $30 \mathrm{t} \mathrm{ha}^{-1}$, em solo com características físicas semelhantes ao do presente estudo, e pobre em matéria orgânica.

O incremento nas produções total e comercial de raízes, em função do emprego do biofertilizante, pode ser explicado pelo fato de que aplicação de fertilizantes orgânicos na forma líquida proporciona maior deslocamento dos nutrientes necessários para as plantas
(SOUZA \& RESENDE, 2003), por possuir na sua composição, nutrientes mais facilmente disponíveis, quando comparados a outros adubos orgânicos e pode promover melhoria das propriedades químicas do solo (GALBIATTI et al., 1991), isso porque o fornecimento de biofertilizante no solo eleva os teores de $\mathrm{P}, \mathrm{Ca}, \mathrm{Mg}$ e K (VARGAS, 1990). Pinheiro \& Barreto (2000) relatam que a fertilização com biofertilizante associado ao esterco bovino, proporciona maiores produções comerciais nas hortaliças pepino, berinjela, tomate, alface e pimentão. Vázquez et al. (1995) verificaram aumento significativo no rendimento de bulbos na cebola utilizando biofertilizante bovino. No melão, a fertirrigação com biofertilizante associado com adubos minerais, aplicado diariamente, proporcionou produção de 45,5 $\mathrm{t} \mathrm{ha}^{-1}$ de frutos, superior estatisticamente à produção de $42 \mathrm{t} \mathrm{ha}^{-1}$, obtida apenas com o fornecimento de adubos minerais (FERNANDES \& TESTEZLAF, 2002).

Nas condições em que se realizou o presente estudo, evidenciou-se que a batata-doce responde de forma positiva à adubação orgânica, sendo a associação do esterco bovino com o biofertilizante, a forma mais recomendada para a fertilização orgânica da cultura.

\section{CONCLUSÕES}

As doses de 26 e $25 \mathrm{t} \mathrm{ha}^{-1}$ de esterco bovino foram responsáveis pelo número de raízes comerciais por planta, na presença e ausência de biofertilizante, respectivamente; 
O peso médio de raízes comerciais aumentou linearmente com as doses de esterco bovino, sendo superior na presença do biofertilizante;

A dose 21,3 t ha-1 de esterco bovino, combinada com o biofertilizante, deve ser recomendada para elevar a produtividade comercial da batata-doce. Porém, o emprego de esterco bovino de forma isolada, na dose de $25 \mathrm{t} \mathrm{ha}^{-1}$, também atende a esse propósito.

\section{REFERÊNCIAS BIBLIOGRÁFICAS}

CHAVES, L. H. G.; PEREIRA, H. H. G. Nutrição e adubação de tubérculos. Campinas: Cargill, 1985. 97 p.

EMPRESA BRASILEIRA DE PESQUISA AGROPECUÁRIA. Centro Nacional de Pesquisa de Hortaliças. Cultivo da batata-doce (Ipomoea batatas (L.) Lam). 3. ed. Brasília, DF: Ministério da Agricultura, do Abastecimento e Reforma Agrária, 1995. (Instruções técnicas, 7).

EMPRESA BRASILEIRA DE PESQUISA AGROPECUÁRIA. Centro Nacional de Pesquisa de Solos. Sistema Brasileiro de Classificação de Solos. Brasília, DF, 1999. 412 p.

FERNANDES, A. L. T.; TESTEZLAF, R. Fertirrigação na cultura do melão em ambiente protegido, utilizando-se fertilizantes organominerais e químicos. Revista Brasileira de Engenharia Agrícola e Ambiental, Campina Grande, v. 16, n. 1, p. 122-126, 2002.

FERNANDES, M. C. A.; LEAL, M. A. A.; RIBEIRO, R. L. D.; ARAÚJO, M. L.; ALMEIDA, D. L. Cultivo protegido do tomateiro sob manejo orgânico. A Lavoura, Rio de Janeiro, n. 634, p. 44-45, 2000.

FERREIRA, M. E.; CASTELLANE, P. E.; CRUZ, M. C. P. Nutrição e adubação de hortaliças. Piracicaba: Potafos, 1993. 487 p.

FILGUEIRA, F. A. R. Novo manual de olericultura: agrotecnologia moderna na produção e comercialização de hortaliças. 2. ed. Viçosa: UFV, 2000. 412 p.

FREITAS, S. P.; SEDIYAMA, T.; SEDIYAMA, M. A. N.; SILVA, A. A. Efeito de composto orgânico na produção da batata-doce (Ipomea batatas L.) Lam.; na incidência de plantas daninhas e na eficiência do diuron. Revista Ceres, Viçosa, v. 46, n. 265, p. 251-265, 1999.
GALBIATTI, J. A.; BENECASA, M.; LUCAS JÚNIOR, J.; JOSÉ-LUI, J. Efeitos da incorporação de efluentes de biodigestor sobre alguns parâmetros do sistema soloplanta, em milho. Revista Científica, Piracicaba, v. 19, n. 2, p. 105-118, 1991.

GALVÃO, J. C. C.; MIRANDA, G. V.; SANTOS, I. C. Adubação orgânica. Revista Cultivar, Pelotas, n. 9, p. 3841, 1999.

HOLlANDA, J. S. Preparo do solo, adubação e plantio de batata-doce. In: ENCONTRO DE PROFESSORES, PESQUISADORES E EXTENCIONISTAS DE OLERICULTURA DO RIO GRANDE DO NORTE, 1990, Mossoro. Anais... Mossoró: UFRN, 1990. p. 14-26.

PINHEIRO, S.; BARRETO, S. B. "Mb-4" - agricultura sustentavel, trofobiose e biofertilizantes. Alagoas: MIBASA, 2000. 273 p.

PRAXEDES, M. G. Avaliação de características agronômicas da cenoura (Daucus carota $L$.) cultivada com biofertilizante. 2000. 22 f. Trabalho de Conclusão de Curso (Graduação em Agronomia) - Universidade Federal da Paraíba, Areia, 2000.

SANTOS, A. C. V. A ação múltipla do biofertilizante líquido como ferti fitoprotetor em lavouras comerciais. In: ENCONTRO DE PROCESSOS DE PROTEÇÃO DE PLANTAS, 1., 2001, Botucatu. Anais... Botucatu: Unesp, 2001. p. 91-96.

SANTOS, A. C. V. Biofertilizante líquido, o defensivo da natureza. Niterói: Emater-Rio, 1992. 16 p. (Agropecuária fluminense, 8).

SANTOS, J. F.; OLIVEIRA, A. P.; ALVES, A. U.; DORNELAS, C. S. M.; BRITO, C. H.; NÓBREGA, J. P. R. Produção de batata-doce adubada com esterco bovino em solo com baixo teor de matéria orgânica. Horticultura Brasileira, Brasília, v. 24, n. 1, p. 103106, 2006.

SENO, S.; SALIBA, G. G.; PAULA, F. J.; KOGA, P. S. Efeitos de doses de fósforo e esterco de galinha na produção do alho (Allium sativum L.). "Roxo Pérola de Caçador”. Científica, São Paulo, v. 24, n. 1, p. 127-133, 1996. 
SILVA, J. B. C.; LOPES, C. A.; MAGALHÃES, J. S. Cultura da batata-doce. In: CEREDA, M. P. Agricultura: tuberosas amiláceas latino americanas. São Paulo: Cargill, 2002. v. 2, p. 449-503.

SOARES, K. T.; MELO, A. S.; MATIAS, E. C. A cultura da batata-doce (Ipomoea batatas (L.) Lam). Joao Pessoa: Emepa-PB, 2002. 26 p. (Documentos, 41).

SOUZA, A. P. Efeitos de diferentes fontes de adubação argânicos sobre a produtividade de cenoura (Daucus carota L.). 1990. 74 f. Trabalho de Conclusão de Curso (Graduação em Agronomia) - Universidade Federal da Paraíba, Areia, 1990.
SOUZA, J. L.; RESENDE, P. Manual de horticultura orgânica. Viçosa: Aprenda fácil, 2003. 564 p.

TRANI, P. E.; TAVARES, M.; SIQUEIRA, W. J.; SANTOS, R. R.; BISÃO, L. L.; LISBÃO, R. S. Cultura do alho: recomendação para seu cultivo no Estado de São Paulo. Campinas: IAC, 1997.

VARGAS, A. M. El biol: fuente de fitoestimulantes en el desarrollo agrícola: programa especial de energias. Cochabamba: UMSS-GTZ, 1990. 79 p.

VÁZQUEZ, J. O. S.; RODRÍGUEZ, A. C.; HERNÁNDEZ, J. A. Utilizacion de un biofertilizante en el cultivo de cebolla (Allium cepa L.) en Chapingo, Mexico. Revista Chapingo: Série Horticultura, Chapingo, v. 1, p. 95-99, 1995. 